\title{
Проблеми вирощування щуки звичайної Esox lucius y лабораторних умовах
}

\section{Ольга Титюк, Ярослав Омельковець, Ярослав Степанюк}

Східноєвропейський національний університет імені Лесі Українки

Адреса для листування: tytiuk.olha@eenu.edu.ua

Отримано: 14.04.20; прийнято до друку: 20.06.20; опубліковано: 02.09.20

Резюме. У роботі з'ясовано основні проблеми, що виникають під час вирощування риб у лабораторних умовах. Вирощування риб необхідне для проведення екологічних досліджень, вивчення морфогенезу систем органів та інших досліджень, де потрібен постійний контроль за рибами на різних стадіях розвитку. Під час інкубації ікри в лабораторії виникають проблеми, які пов'язані передусім із неможливістю забезпечити постійну проточність інкубаторів 3 ікрою. Під час вирощування щуки звичайної (Esox lucius) через велику щільність ікри важливим є своєчасна і швидка боротьба 3 грибами роду Saprolegnia, забезпечення постійної заміни води в інкубаторах. Особливістю щуки є нерест за низьких температур, тому важливим є контроль за температурою води, де розвиваються ікра та личинки.

Ключові слова: Esox lucius, Saprolegnia, ікра, личинки, онтогенез, екологічні фактори.

\section{Problems of the Northern Pike Esox lucius Cultivation in the Laboratory Conditions}

\section{Olha Tytiuk, Yaroslav Omelkovets, Yaroslav Stepanyuk}

Lesya Ukrainka Eastern-European National University, Lutsk, Ukraine

Address for correspondence: tytiuk.olha@eenu.edu.ua

\begin{abstract}
In the article, main concerns arising both at the time of incubation and while cultivating fish in laboratory conditions were identified. The main morphological features of fishes at different stages of ontogenesis used to determine the developmental stage of the northern pike Esox lucius were described. The cultivation of fishes in the laboratory conditions is necessary for ecological researches, for the study of morphogenesis of organ systems, and other studies where fishes should be continuously monitored at different development stages. In the laboratory, during the incubation of the eggs, problems can mainly emerge from the impossibility to ensure the constantly running water for the incubation boxes with eggs. During the cultivation of northern pike Esox lucius, because of the high density of eggs, the timely and prompt fight against the water fungs of the genus Saprolegnia is very important. It is necessary to take away the eggs affected by fungs. It is important to regularly replace the water in the incubation boxes with pikes. The new water should not differ a lot in its chemical composition. The particularity of the northern pike Esox lucius is the spawning at low temperatures, that is why it is very important to keep in check the water temperature where eggs and larvae are being developed. The pace of development of the northern pike Esox lucius in laboratory conditions is accelerated if compared to the natural ones. Incorrect conditions of eggs fertilization and incubation as well as feeding larvae with food inappropriate in size can cause the mass mortality of fishes at some critical stages of their development or the developmental impairment. During the research, such morphological impairments of embryos of the northern pike Esox lucius is the anlage of two heads and, on the contrary, the head not being fully developed up to the moment of hatching were detected.
\end{abstract}


Keywords: Esox lucius, Saprolegnia, eggs, larvae, ontogeny, environmental factors.

\section{ВСТУП}

Розведення і вирощування риб - на сьогодні досить розвинений напрям тваринництва у складі агропромислового комплексу. Особливо багато уваги приділяється цінним промисловим (кларієвий сом Clarias gariepinus, форель райдужна Salmo gairdneri) або декоративним видам риб (короп коі Cyprinus carpio haematopterus). Постійно продовжуються пошуки нових методів та способів вирощування риб у великій кількості 3 мінімальними затратами.

Необхідною складовою раціонального риборозведення $\epsilon$ наявність у ставках та озерах щуки звичайної Esox lucius (Linnaeus, 1758), оскільки за ії відсутності різко зростає чисельність «смітних» видів риб. Щука звичайна здійснює регуляцію чисельності промислових видів, знищуючи хворих особин, та сприяе відтворенню водних біоресурсів. 3-поміж інших хижаків щука звичайна найкраще адаптовується у водоймах нашої місцевості і широко використовується в рибних господарствах.

Незважаючи на масове розведення E. lucius, детального опису іiі онтогенезу немає. В літературі переважно описано постембріональний розвиток E. lucius [1-4] і лише деякі роботи містять опис ембріонального періоду [5-6]. Зазвичай для дослідження запліднену ікру, передличинок або личинок виловлюють із водойм i досліджують у лабораторних умовах. Для морфологічних та екологічних досліджень необхідним $\epsilon$ інкубування усіх стадій розвитку в лабораторії, оскільки це надає можливість постійно спостерігати за онтогенезом. Детальний опис усіх стадій розвитку виду дасть змогу створити таблицю нормального розвитку, яка необхідна для опису та міжвидового порівняння морфогенезу будь-якого органа чи системи органів.

На сьогодні розроблені методики для вирощування лише окремих риб у лабораторних умовах [7-9]. Загальноприйнятою методикою інкубації ікри E. lucius $€$ використання апарату Вейса [10] або проточних ємностей об'ємом 20-40 літрів [11]. $\mathrm{y}$ наукових лабораторіях створення спеціалізованих приміщень для розміщення необхідних конструкцій не завжди є можливим. Вирощування в лабораторних умовах може значно вплинути на процес розвитку, тому необхідно врахувати всі можливі негативні фактори.

Метою нашої роботи було виявити основні проблеми вирощування E.lucius у лабораторних умовах. Для цього необхідно було описати розвиток виду на окремих стадіях розвитку та здійснити порівняльний аналіз отриманих результатів 3 попередніми дослідженнями інших авторів.

\section{МАТЕРІАЛИ Й МЕТОДИ ДОСЛІДЖЕНЬ}

Запліднену ікру E.lucius отримували в нерестовий сезон у приватному сільськогосподарському підприємстві «Павлівська риба» (4 квітня 2016 року) та приватному господарстві П. В. Басалика (Горохівський район) (23 березня 2016 року). Запліднення ікри E. lucius здійснювали сухим методом: змішування ікри та сперми, $з$ додаванням води пізніше. Після цього транспортування проводилось у пакетах, наповнених киснем. Вирощування личинок проводили в лабораторії гістології та морфогенезу Східноєвропейського національного університету імені Лесі Українки. Ікру розміщували в плоских широких контейнерах (товщиною у 2 ікринки). Товщина шару води над ікрою не перевищувала 2 см для достатнього газообміну. Личинок після вилуплення переміщали у ємності об'ємом 5 л. Температура води протягом інкубації становила $+19^{\circ} \mathrm{C}$.

Розвиток ікри та личинок контролювали під мікроскопом МБС-10. Ембріональні стадії розвитку визначали за таблицями нормального розвитку щуки звичайної за Котляревською (1969) [5], личинкові - за Шамардіною (1957) [3]. Для порівняння особливостей розвитку щуки звичайної іiі личинок отримували у ДП «Рибгосп «Цумань» ВАТ Волиньрибгоспу ТзОВ «Цумань - Риба» (Ківерцівський район) та підприємстві «Павлівська риба».

Фіксували матеріал у $10 \%$ розчині нейтрального формаліну. Після фіксації дегідратацію здійснювали у спиртах зростаючої концентрації $(60 \%, 70 \%, 80 \%, 90 \%, 100 \%)$. Після дегідратації матеріал поміщали у суміш спирт-о-ксилол та о-ксилол. Після цього матеріал витримували в о-ксилол-парафіновій суміші в термостаті $\left(+37^{\circ} \mathrm{C}\right)$ та в двох порціях гістологічного парафіну (Paraplast) 3 температурою плавлення $+56^{\circ} \mathrm{C}$. Тривалість витримування матеріалу в розчинах встановлювали з урахуванням стадії розвитку 
Проблеми вирочування шуки звичайної Esox lucius у лабораторних умовах

та розмірів об'єкту. Зрізи отримували відповідно до стандартних гістологічних методик на санному мікротомі (MC-2, Точмедприбор) 3 використанням одноразових лез (Patho cutter R 35, Erma Inc., Японія).

Фотографування фіксованого матеріалу та гістопрепаратів здійснювали в Центрі колективного користування науковими приладами «Animalia» Інституту зоології ім. I. I. Шмальгаузена за допомогою дослідницьких мікроскопів Leica M165C та Zeiss Axio Imager M1.

Проведення дослідження здійснювали відповідно до вимог Етично-наукової комісії Східноєвропейського національного університету імені Лесі Українки.

\section{РЕЗУЛЬТАТИ ТА ЇХ ОБГОВОРЕННЯ}

\section{Запліднення}

Зазвичай під час запліднення в рибних господарствах ікра контактує 3 водою зі ставків, де утримуються дорослі самці і самки. Після розміщення ікри в контейнери в лабораторних умовах першою проблемою $\epsilon$ швидкий розвиток грибів роду Saprolegnia (клас Oomycetes). У природних умовах вони уражають незапліднену й ушкоджену ікру. Крім того, у кожній водоймі вміст Saprolegnia відрізняється. В лабораторних умовах часто уражається неушкоджена ікра, яка нормально розвивається. Це відбувається внаслідок стабільної температури, великої щільності ікри, а також відсутності циркуляції води. Для зменшення ступеня уражуваності постійно відбирали уражену ікру та три рази на день змінювали воду, в якій інкубується ікра. Висловлюємо припущення, що альтернативним методом для попередження ураження ікри може бути запліднення ікри 3 додаванням розчину Гольтфретера замість води 3 водойм, де утримуються статевозрілі особини [12]. Розчин Гольтфретера - це фізіологічний розчин 3 такою концентрацією солей: $\mathrm{CaCl}_{2}-1,5 \mathrm{MM}$, $\mathrm{NaCl}-30 \mathrm{mM}, \mathrm{KCl}-1 \mathrm{mM}, \mathrm{MgCl} \times 6 \mathrm{H}_{2} \mathrm{O}-0,25$ $\mathrm{MM}, \mathrm{NaHCO}_{3}-1 \mathrm{мM}$, ЕДТА - 0,25 мМ)

Ембріональний період - період вилуплення

Закладка очних міхурів (початок органогенезу) відбувається на третю добу після запліднення. Це відповідає IV етапу нормального розвитку E.lucius за Котляревською [5]. У таблицях нормального розвитку відсутні дані про час початку цього етапу, оскільки запліднена ікра була відібрана 3 природних водойм i неможливо було встановити час запліднення [5].
На шосту добу після запліднення починається VI етап розвитку щуки звичайної. Розмежувати VI та VII етапи розвитку перед вилупленням складно. Одною з основних ознак $\epsilon$ накопичення (VI етап) та вивільнення секрету (VII етап) у залозах вилуплення (рис. 1,2). Окрім того, личинка на VI етапі має багато пігментних клітин на голові та жовтку, зявляється пігментація очей (рис. 2). За температури $+12-14^{\circ} \mathrm{C}$ та постійної проточності інкубаторів VI етап наступає на 12 добу [11]. Це пояснюється прямолінійною залежністю тривалості розвитку від температури води, у якій розвивається зародок [13-15]. Отже, ембріональний розвиток у лабораторних умовах значно пришвидшений.
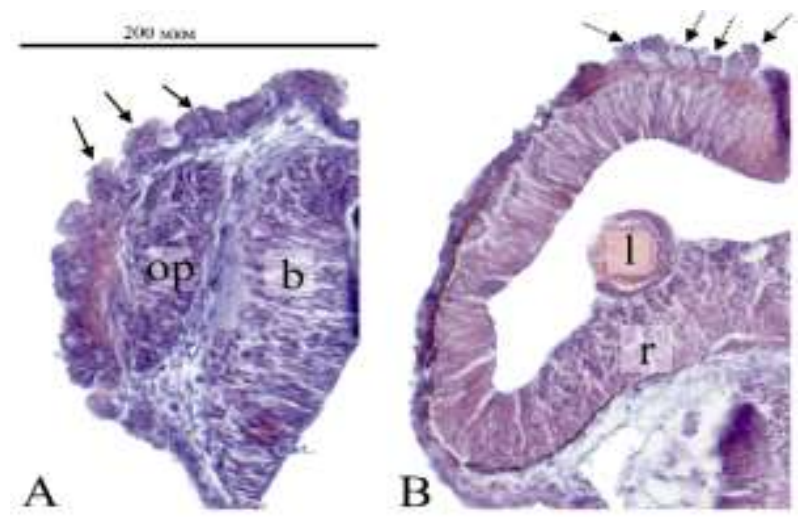

Рис. 1. Переріз через залози вилуплення E. lucius на VI (A) ma VII (B) етапах розвитку: ор - нюхова плакода;

$$
\begin{gathered}
b-\text {-мозок; } \\
r \text {-сітківка; } \\
l-\text {-кришталик. }
\end{gathered}
$$

Суцільна стрілка вказує на залози з накопиченим секретом; пунктирна - залози без секрету.

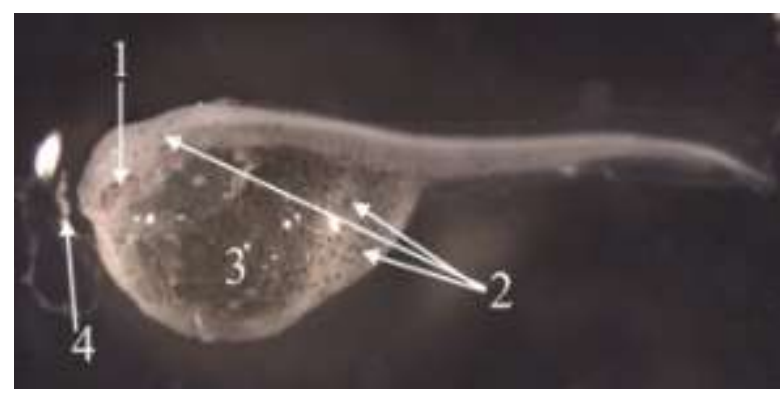

Рис. 2. Загальний вигляд передличинки

E. lисіиs на момент вилуплення:

$$
1 \text { - око; }
$$

2 - пігментні клітини; 3-жовток;

4 - секрет залоз вилуплення. 
У лабораторних умовах VI та VII етапи розвитку відбуваються 3 різницею близько 12 год, тоді коли при моделюванні природних умов близько 2 діб [11]. Отже, вилуплення передличинок (VII етап розвитку за Котляревською, або I етап розвитку за Шамардіною) у лабораторних умовах відбувається на 6-й день після запліднення. Варто зазначити, що швидкість розвитку може залежати від температури води та вмісту кисню у воді [16].

\section{Личинковий період}

У лабораторних умовах II етап розвитку за Шамардіною настає на сьому добу після запліднення, а відібраних у природних умовах личинок аж на 12-ту добу. У цей час око повністю пігментоване, добре помітні зяброві кришки, а також зачатки грудних плавців (рис. 3).

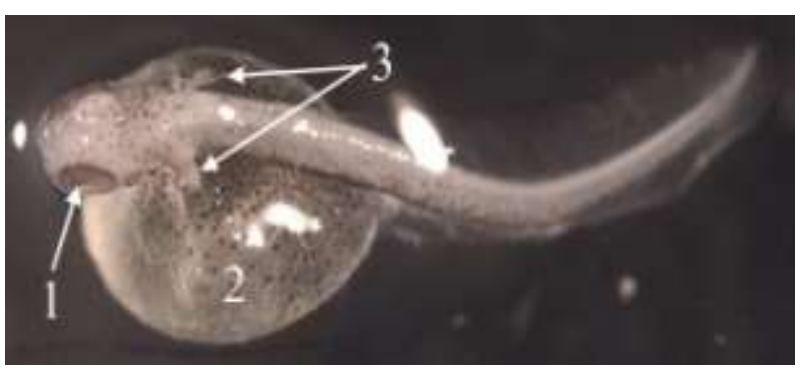

Pис. 3. Загальний вигляд личинки

E. lucius на II етапі личинкового розвитку:

$$
\begin{gathered}
1 \text {-око; } \\
2 \text {-жовток; }
\end{gathered}
$$$$
3 \text {-зачатки грудних плавиів. }
$$

Перехід на зовнішнє живлення відбувається при зникненні запасів жовтка. На V етапі розвитку за Шамардіною у личинок уже з'являються мезенхімні промені у плавцях (рис. 4). У вирощуванні личинок наважливішим є правильний вибір корму в період переходу на зовнішнє живлення, а саме зміна корму 3 інфузорій, личинок артемій до морожених дафній та циклопів.

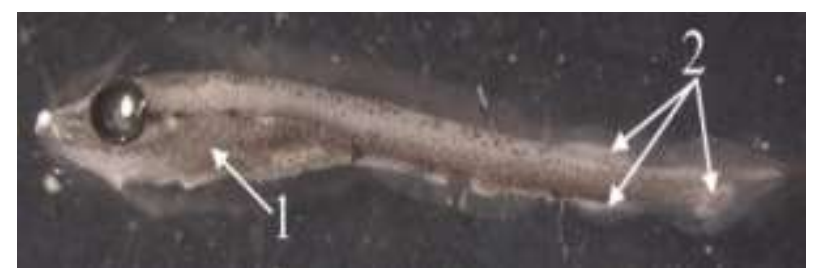

Puc. 4. Загальний вигляд личинки

E. lucius на V eтапі личинкового розвитку: 1 - зябра;

2 -мезенхімні промені плавиів.
Проблемою, яка виникає в лабораторних умовах під час вирощування щуки звичайної, $\epsilon$ забезпечення низьких температур води. У природних умовах нерест відбувається за температури води $+8-11^{\circ} \mathrm{C}$. Під час швидкого підвищення температури води, при переміщенні ікри, передличинок та личинок у лабораторні умови, відбувається швидке зниження вмісту кисню у воді, а також тепловий шок, що спричиняє загибель риби. Для попередження негативних наслідків, після переміщення ікри та передличинок у лабораторію, утримували іiі в холодильних камерах та поступово піднімали температуру води до $+19^{\circ} \mathrm{C}$.

Іншою проблемою під час інкубації ікри $€$ підбір води для триразової ii підміни у ємностях 3 ікрою. Вода 3 природних водойм може містити великий вміст грибів роду Saprolegnia, дуже відрізнятись за хімічним складом, а також бути забрудненою шкідливими хімічними речовинами. Водопровідна вода зазвичай містить надмірний вміст хлору та $є$ жорсткою. Для зменшення впливу хлору воду необхідно відстоювати. Для зниження вмісту іонів кальцію та магнію у водопровідній воді застосовували кондиціонер для підготовки води в акваріумах (Tetra Aqua Safe), який зв'язує хлор та іони важких металів. Зазвичай під час інкубації ікри у водопровідній воді оболонки ікри стають міцнішими (товстішими) внаслідок нашарування солей. Це унеможливлює своєчасне вилуплення личинок, оскільки вихід личинок E. lucius з ікри у нормі здійснюється внаслідок розриву оболонок хвостом [5]. Якщо оболонки ущільнені, то розриву від рухів тіла не відбудеться. В такому разі вилуплення може відбутися після розм'якшення оболонки поблизу голови під дією ферментів залоз вилуплення. Часто це призводить до того, що голова контактує із зовнішнім середовищем, а тулуб залишається вкритим оболонкою ікри. Якщо в цей період личинку звільнити від оболонки за допомогою пінцета та скальпеля, личинка розвиватиметься далі нормально, а якщо не звільняти - вона гине. Під час дослідження були виявлені такі морфологічні порушення ембріонів, як закладка двох голів E. lucius та, навпаки, відсутність нормальної сформованої голови аж до моменту перед вилупленням. Часто порушення розвитку ікри в лабораторних умовах виникає внаслідок стимулювання овуляції недозрілих ооцитів. Після їх запліднення утворюється збільшений превітеліновий простір, зародки розвиваються 3 порушенням (з викривленим тілом). 


\section{ВИСНОВКИ}

Порівнюючи ембріони та личинки щуки звичайної Esox lucius на різних стадіях розвитку, які вирощені у природних та лабораторних умовах, морфологічних відмінностей не спостерігали. Темп розвитку E. lucius в лабораторних умовах пришвидшений порівняно 3 природними. Основними проблемами інкубації ікри в лабораторії $\epsilon$ швидке ураження ікри грибами роду Saprolegnia, забезпечення заміни води близькою за фізико-хімічними показниками, а також дотримання температурного режиму.

\section{Подяки}

Автори висловлюють вдячність П. Г. Сарабуні， П. В. Басалику та Л. П. Попик за можливість отримати запліднену ікру щуки звичайної i личинок різних стадій для проведення порівняльного аналізу розвитку риб у природних та лабораторних умовах.

\section{ЛIТЕРАТУРА}

1. Moser, H. G. Ontogeny and systematics of fishes. The american society of ichthyologists and herpetologists: Lawrence, 1984; $760 \mathrm{p}$.

2. Коблицкая, А. Определитель молоди пресноводных рыб. Легкая и пищевая промышленность: Москва, 1981; 208 с.

3. Шамардина, И. П. Этапы развития щуки. Труды института морфологии животных им. А. Н. Севериова; 1957, 16, с 237-298.

4. Макеева, А.; Павлов, Д.; Павлов, Д. Атлас молоди пресноводных рыб России. Товарищество научных изданий КМК: Москва, 2011, 383 с.
5. Котляревская Н. В. Процесс вылупления у щуки Esox lucius L. Вопросы Ихтиологии 1969, 9 (1), c 116-128.

6. Dorier, A. A Propos de l'oeuf et de l'alevin de Brochet. Bull. Fr. Piscic. 1938, 110, pp 61-73.

7. Нейфах, А. А.; Тимофеева, М. Я.; Георгиев, Г.П. Молекулярная биология прочессов развития. Наука: Москва, 1977, 311 с.

8. Kemp, A. Rearing of embryos and larvae of the Australian lungfish, Neoceratodus forsteri, under laboratory conditions. Copeia 1981, (4), p 776.

9. Sule, O. D.; Adikwu, I. Embryonic development in Clarias gariepinus (Buchell, 1822) under laboratory conditions. Anim. Res. Int. 2017, 1 (2), pp 81-85.

10. Владовская, С.; Гамаюн, Е. Использование щуки в условиях интенсивного рыбоводства. Центральный научно-исследовательский институт информации и технико-экономических исследований рыбного хозяйства Министерства рыбного хозяйства СССР: Москва, 1980, 31 с.

11. Девицина Г. В. Развитие органов химической рецепции в онтогенезе обыкновенной щуки Esox luсіиs. Вопросы Ихтиологии; 1998, 38 (4), с 537-547.

12. Tytiuk, O.; Stepanyuk, Y.; Yaryhin, O. The influence of fixatives on the validity of histological preparations of olfactory organ in Teleostei. Vestn. Zool.; 2018, 52 (6), pp 521-528.

13. Макеева, А. П. Эмбриология рыб. Изд-во МГУ: Москва, 1992, 216 с.

14. Kamler, E. Ontogeny of Holk-aeeding aish: An ycological zerspective. Rev. Fish Biol. Fish. 2002, 12 (1), pp 79-103.

15. Reproductive Biology and Phylogeny of Fishes (Agnathans and Bony Fishes); Jamieson, B. G. M., Ed.; Science Publishers: Enfield, 2009, 538 p.

16. Güralp, H.; Pocherniaieva, K.; Blecha, M.; Policar, T.; Pšenička, M.; Saito, T. Development, and effect of water temperature on development rate, of pikeperch Sander lucioperca embryos. Theriogenology, 2017, 104, pp 94-104. 